This item was submitted to Loughborough's Research Repository by the author.

Items in Figshare are protected by copyright, with all rights reserved, unless otherwise indicated.

\title{
Effects of opening roller speed on the fiber and yarn properties in open-end friction spinning
}

\section{PLEASE CITE THE PUBLISHED VERSION}

http://dx.doi.org/10.1177/004051759506501001

\section{PUBLISHER}

Sage (๑) Textile Research Institute)

\section{VERSION}

AM (Accepted Manuscript)

\section{PUBLISHER STATEMENT}

This work is made available according to the conditions of the Creative Commons Attribution-NonCommercialNoDerivatives 4.0 International (CC BY-NC-ND 4.0) licence. Full details of this licence are available at: https://creativecommons.org/licenses/by-nc-nd/4.0/

\section{LICENCE}

CC BY-NC-ND 4.0

\section{REPOSITORY RECORD}

Ulku, S., B. Ozipek, and Memis Acar. 2019. "Effects of Opening Roller Speed on the Fiber and Yarn Properties in Open-end Friction Spinning". figshare. https://hdl.handle.net/2134/22053. 


\title{
Effects of Opening Roller Speed on the Fiber and Yarn Properties in Open-End Friction Spinning
}

\author{
S. ULKU \\ Department of Textile Engineering, Uludag University, Gorukle Campus, 16384 \\ Bursa, Turkey \\ B. OZIPEK \\ Department of Textile Engineering, Istanbul Technical University, Istanbul, \\ Turkey \\ M. ACAR \\ Department of Mechanical Engineering,Loughborough University of Technology, \\ Loughborough LE11 3TU, U.K.
}

\begin{abstract}
The opening roller system for fiber separation in an open end spinning process is known to cause considerable fiber breakage. We have investigated fiber breakage at different opening roller speeds and the relationship between breakage and the properties of friction spun yams made from cotton, polyester, viscose, and acrylic fibers. A high level of fiber damage caused by the opening rollers occurs at high speeds. The level of damage differs from one sort of material to another. There is a great deterioration in properties when yarns are processed at high opening roller speeds.
\end{abstract}

One of the most essential operations of the open- end spinning process is to open and separate the sliver into individual fibers that can be carried by the air stream to the spinning unit. As a fiber-separating device, the opening roller system gives a high degree of separation, but it is achieved at the expense of fiber breakage. Breakage is influenced by the mechanical and physical properties of the fibers, the feed rate and fiber configurations in the feed sliver, and the design of the opening roller and its speed.

Mansour and El Messiry [7] showed that the opening roller causes fiber damage that differs from one cotton type to a nother. Salhotra and Chattopadhyay [9] showed that the number of fibers that break increases as the opening roller speed rises. Salhotra et al. [11] proposed a model based on the numberlength relationship of the fibers, before and after the breakage, for estimating the probabilities of multi-segmental breakage. Chattopadhyay and Sinha [3] studied the length distribution pattern of the broken parts of fibers generated during separation and showed that it follows a gamma distribution. Dyson [4] showed that the choice of opening roller speed can significantly affect the open-end rotor spun yarns due to fiber breakage. Also Mansour and El Messiry [7] found great deterioration in rotor spun yam properties when using consumed rollers. They reported that this deficiency in yam quality is mainly because the degree of opening becomes very low when using consumed rollers. Abadaer [1] reported the effects of opening roller speed varied from one fiber material to another, and the fibers responded in different ways and with different levels of results. Salhotra and Chattopadhyay [10] showed that the vigorous action of the teeth of the opening rollers also causes a reduction in fiber tenacity and elongation.

The characteristics of the opening roller clothing must be chosen to suit the fiber being spun. The most significant parameters are tooth form, working angle, number of teeth per unit area, and surface finish of the teeth. The optimum conditions are the result of a com- promise between these parameters. Simpson and Murray [13] found that a combing-roll wire front (forward rake) angle of $15^{\circ}$ yielded better results in terms of trash buildup in the rotor, fiber parallelization, and yam strength. Dyson [4] found that fiber breakage effects can be minimized by using low sliver linear density, a high speed of sliver input, a slow combining roller speed, and a combing roller with a low wire- point density. He pointed out that the 
optimum wire front angle is close to $80^{\circ}\left(10^{\circ}\right.$ forward rake), and the roller of lowest wire point density is preferable for use with cotton fibers. Compared with wire, a pinned roller is kinder to fibers and suffers from less wear, damage, and fiber shortening [6].

Ozipek [8] reported that after the opening action in rotor spinning, the level of reduction in fiber length and tensile properties varied for different kinds of acrylic fibers. Ozipek also showed that there was a general tendency for tenacity values of different acrylic yarns to decrease as the opening roller speed increased. Sikder [12] showed that when the opening roller speed of the friction spinning machine increased, yarn tenacity and elongation atbreak decreased: The probable reason for this was that as the roller speed increased, some fibers broke due to the higher beater speed.

In this work, we have studied fiber breakage at different opening roller speeds and investigated the relationship between fiber breakage and properties of friction spun yarns made from cotton, polyester, viscose, and acrylic fibers. We used the experimental rig de- scribed by Ulku et al. [14] to collect fiber samples, which we fitted with the same opening roller as used on a Platt Saco Lowell Masterspinner machine. This roller has a wire front angle of $80^{\circ}$ and a wire point density of 15 points $/ \mathrm{cm}^{2}$; these specifications are almost the same as those recommended by Simpson and Murray [13]. All process parameters other than opening roller speed were kept constant for all the experiments in order to analyze only the effect of the opening roller speed.

\section{Materials and Methods}

We used cotton (28.9 mm effective length and 1.31 dtex), polyester (38.0 mm length and 1.50 dtex), viscose ( $40.0 \mathrm{~mm}$ length and 1.30 dtex) and acrylic $(40.0 \mathrm{~mm}$ length and 1.40 dtex) fibers in the form of second draw frame slivers. The linear densities of these slivers were 3.19, 2.60, 5.10, and $3.10 \mathrm{ktex}$, respectively.

The experimental rig consisted of feeding, opening, and air suction units as illustrated in our earlier work [14]. The feeding and opening units used on the test rig were standard components on Platt Saco Lowell OE spinning machines. After feeding the drawn sliver for approximately 5 minutes each time, we then stopped the feed and the suction, and took the fiber samples from the collecting chamber, which is positioned at the end of the extension piece connected to the opening unit. In the opening phase, we also used a Photec IV $16 \mathrm{~mm}$ cine-camera, described earlier [14] for the high-speed photography at a rate of 20,000 half- frame pictures per: second, and applied the method we developed to analyze fiber straightness. The list of samples taken from the collecting chamber and the corresponding test conditions are given in Table I. The axial air flow speeds given in the table are for the center of theperpendicular plane in the extension piece, which forms a bridge between the opening roller and the uniform channel that guides the fibers. The variation in this air flow speed across the section of the tube was negligible \{14]. The distance of the perpendicular plane from the opening roller was $28 \mathrm{~mm}$.

We determined fiber length characteristics, tenacity, and elongation at break for samples drawn from slivers as well as from the depositions in the collecting chamber. We measured fiber length using single fiber, beard diagram, and fibrograph techniques. We measured fiber tenacity and elongation at break with a fibrograph for cotton fibers and a MC Deframe single fiber tester for polyester, viscose, and acrylic, using a $10 \mathrm{~mm}$ gauge length and 50 specimens for each fiber sample. We made comparisons of these fiber characteristics for given test conditions just for the same materials.

To investigate the effects of fiber breakage on yarn properties, we fed the same slivers into the PSL Masterspinner friction spinning machine. The 30 tex yarns were produced at a $150 \mathrm{~m} / \mathrm{min}$ delivery speed. The list of the yarn samples and the corresponding test conditions are given in Table II. We compared the yams produced from the same fiber material with different opening roller speeds, on the basis of yarn count, tenacity and elongation at break, twist number, and irregularity. We used the following devices for these purposes: System Autosorter 3, Uster Tensorapid, Baranca automatic twist tester, and Ulster tester 3 . We also used the untwist-twist method to measure twist. Although this method is not widely used for measuring the twist of OE yarns, we have used it in this study for relative comparison of the yarns.

\section{Results and Discussion}

\section{FIBER LENGTH CHARACTERISTICS}

The results of the analysis of fiber length characteristics before and after opening with different opening roller speeds are given in Figure 1. The figure shows a decrease in 2.5\% span length, 50\% span length, 
mean fiber length, and effective length values for all four fiber types after passing them through the opening roller. The uniformity ratio, upper quartile, and lower quartile also demonstrate similar trends. Accordingly, the coefficient of variation of mean fiber length, percentage of short fibers, and the dispersion increased in all cases.

TABLE I. List of the fiber samples and corresponding test conditions.

\begin{tabular}{|c|c|c|c|c|}
\hline Fiber sample & Fiber material & $\begin{array}{l}\text { Surface speed of } \\
\text { feeding roller, } \\
\mathrm{m} / \mathrm{min}\end{array}$ & $\begin{array}{l}\text { Speed of opening } \\
\text { roller. rpm }\end{array}$ & $\begin{array}{c}\text { Airflow speed } \\
\mathrm{m} / \mathrm{s}\end{array}$ \\
\hline $\mathrm{C}^{*}$ & cotton & - & - & - \\
\hline C4 & cotton & 1.0 & 4000 & 38.06 \\
\hline C5 & cotton & 1.0 & 5000 & 38.06 \\
\hline C6 & cotton & 1.0 & 6000 & 38.06 \\
\hline $\mathrm{C} 7$ & cotton & 1.0 & 7000 & 38.06 \\
\hline C8 & cotton & 1.0 & 8000 & 38.06 \\
\hline C9 & cotton & 1.0 & 9000 & 38.06 \\
\hline $\mathrm{P}^{*}$ & polyester & - & - & - \\
\hline P6 & polyester & 1.0 & 6000 & 38.06 \\
\hline P7 & polyester & 1.0 & 7000 & 38.06 \\
\hline P8 & polyester & 1.0 & 8000 & 38.06 \\
\hline P9 & polyester & 1.0 & 9000 & 38.06 \\
\hline $\mathrm{V}^{*}$ & viscose & - & - & - \\
\hline V4 & viscose & 1.0 & 4000 & 38.06 \\
\hline V5 & viscose & 1.0 & 5000 & 38.06 \\
\hline V6 & viscose & 1.0 & 6000 & 38.06 \\
\hline V7 & viscose & 1.0 & 7000 & 38.06 \\
\hline VS & viscose & 1.0 & 8000 & 38.06 \\
\hline V9 & viscose & 1.0 & 9000 & 38.06 \\
\hline$A^{*}$ & acrylic & - & - & - \\
\hline A5 & acrylic & 1.0 & 5000 & 38.06 \\
\hline A6 & acrylic & 1.0 & 6000 & 38.06 \\
\hline A7 & acrylic & 1.0 & 7000 & 38.06 \\
\hline A8 & acrylic & 1.0 & 8000 & 38.06 \\
\hline A9 & acrylic & 1.0 & 9000 & 38.06 \\
\hline
\end{tabular}

*Drawn from sliver.

TABLE II. List of the yam samples and corresponding test conditions.

\begin{tabular}{|c|c|c|c|c|c|c|}
\hline Yarn sample & Fiber material & $\begin{array}{c}\text { Opening roller } \\
\text { speed, rpm }\end{array}$ & $\begin{array}{c}\text { Air flow } \\
\text { speed, m/s }\end{array}$ & $\begin{array}{l}\text { Friction roller } \\
\text { speed. rpm }\end{array}$ & $\begin{array}{c}\text { Twist } \\
\text { factor } \alpha_{c}\end{array}$ & $\begin{array}{l}\text { Feeding roller } \\
\text { speed. } \mathrm{m} / \mathrm{min}\end{array}$ \\
\hline C14 & cotton & 4000 & 30.3 & 4500 & 4.5 & 1.506 \\
\hline C15 & cotton & 5000 & 30.3 & 4500 & 4.5 & 1.506 \\
\hline C16 & cotton & 6000 & 30.3 & 4500 & 4.5 & 1.506 \\
\hline C17 & cotton & 7000 & 30.3 & 4500 & 4.S & 1.506 \\
\hline C18 & cotton & 8000 & 30.3 & 4500 & 4.5 & 1.506 \\
\hline C18 & cotton & 9000 & 30.3 & 4500 & 4.5 & 1.506 \\
\hline P16 & polyester & 6000 & 30.3 & 3500 & 3.5 & 1.752 \\
\hline Pl7 & polyester & 7000 & 30.3 & 3500 & 3.5 & 1.752 \\
\hline P18 & polyester & 8000 & 30.3 & 3500 & 3.5 & 1.752 \\
\hline Pl 9 & polyester & 9000 & 30.3 & 3500 & 3.5 & 1.752 \\
\hline Vl4 & viscose & 4000 & 30.3 & 4000 & 4.0 & 1.143 \\
\hline Vl5 & viscose & 5000 & 30.3 & 4000 & 4.0 & 1.143 \\
\hline Vl6 & viscose & 6000 & 30.3 & 4000 & 4.0 & 1.143 \\
\hline Vl8 & viscose & 7000 & 30.3 & 4000 & 4.0 & 1.143 \\
\hline V18 & viscose & 8000 & 30.3 & 4000 & 4.0 & 1.143 \\
\hline V19 & viscose & 9000 & 30.3 & 4000 & 4.0 & 1.143 \\
\hline Al6 & acrylic & 6000 & 30.3 & 4000 & 3.25 & 1.500 \\
\hline Al7 & acrylic & 7000 & 30.3 & 4000 & 3.25 & 1.500 \\
\hline Al8 & acrylic & 8000 & 30.3 & 4000 & 3.25 & 1.500 \\
\hline Al9 & acrylic & 9000 & 30.3 & 4000 & 3.25 & 1.500 \\
\hline
\end{tabular}


TABLE III. The correlation coefficients between the speed of opening roller and fiber characteristics.

\begin{tabular}{lcccc} 
& Cotton & Polyester & Viscose & Acrylic \\
\hline 2.5\% Span length & -0.967 & -0.920 & -0.979 & -0.630 \\
50\% Span length & -0.994 & -0.940 & -0.974 & -0.650 \\
Mean fiber length & -0.990 & -0.830 & -0.970 & -0.809 \\
Effective length & $\underline{-0.960}$ & $\underline{-0.930}$ & $\underline{-0.930}$ & $\underline{-0.811}$
\end{tabular}

The correlation coefficients, which we obtained from the regression lines in Figure 1, between the opening roller speed and $2.5 \%$ span length, 50\% span length, mean fiber length, and effective length for cotton, polyester, viscose, and acrylic are given in Table III. The results clearly show that the correlation between fiber length characteristics and opening roller speed is highly significant for cotton, polyester, and viscose, indicating that the choice of opening roller speed can significantly affect fiber length properties. For acrylic fibers, however, there is only a small degree of association between these two factors.
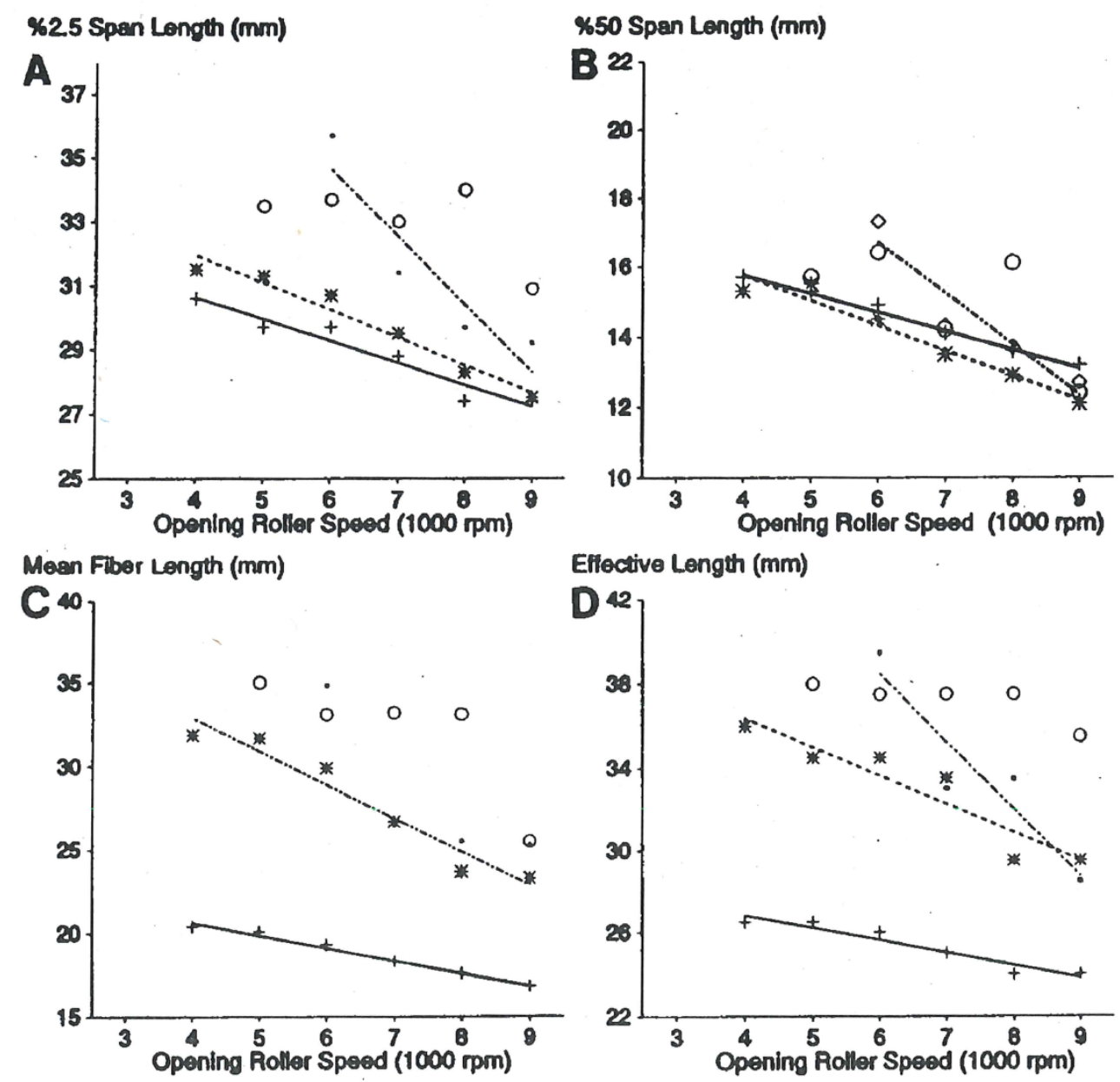

FIGURE I. Relationship between opening roller speed and fiber length. (A) solid line, $y=0.68 x+33.35$; dotted line, $y=$ 2.12x +47.37 ; dashed line. $y=0.86 \mathrm{x}+35.40:+=$ cotton. $\cdot=$ polyester, $*=$ viscose, $\mathrm{O}=$ acrylic. $(\mathrm{B})$ solid line, $y=0.53 x+17.87$; dotted line, $y=1.4 \mathrm{Sx}+25.39$; dashed line, $y=0.71 \mathrm{x}+18.57:+=$ cotton, $\diamond=$ polyester, $*=$ viscose, $\mathbf{O}=$ acrylic. (C) solid line, $y=0.76 x+23.67$; dotted line, $y=2.0 \mathrm{x}+40.90:+=$ cotton, $\cdot=$ polyester, $*=$ viscose, $\mathrm{O}=$ acrylic. $(\mathrm{D})$ solid line, $y=0.60 x+29.23$; dotted line, $y=3.25 \mathrm{x}+58.0$; dashed line. $y=1.38 \mathrm{x}+41.92:+$ = cotton, $\cdot=$ polyester, $*$ = viscose, $\mathbf{O}=$ acrylic. 


\section{FIBER BREAKAGE}

Breakage values for different opening roller speeds have been calculated using the mean fiber lengths before and after the opening process, as shown by $[2,5]$

Fiber breakage $=\left(l_{i}-l_{f}\right) / l_{f}$

where $l_{i}$ is the mean fiber length before opening and $l_{f}$ is the mean fiber length after opening. Fiber breakage values are shown in Table IV.

The increased breakage at higher opening roller speeds can be attributed mainly to two factors: the carrying factor increases with the speed, increasing the likelihood of pin-fiber contact and thus increased fiber damage, and the forces acting on the fiber also increase, resulting in a reduction in the number of fibers slipping around the pins without being damaged.

TABLE IV. The fiber breakage values.

\begin{tabular}{cc}
\hline Fiber sample & Fiber breakage \\
\hline C4 & 0.010 \\
C5 & 0.025 \\
C6 & 0.067 \\
C7 & 0.126 \\
C8 & 0.171 \\
C9 & 0.226 \\
P6 & 0.049 \\
P7 & 0.377 \\
P8 & 0.431 \\
P9 & 0.443 \\
V4 & 0.013 \\
V5 & 0.019 \\
V6 & 0.081 \\
V7 & 0.210 \\
V8 & 0.363 \\
V9 & 0.386 \\
A5 & 0.009 \\
A6 & 0.067 \\
A7 & 0.063 \\
A8 & 0.067 \\
A9 & 0.384 \\
\hline
\end{tabular}

\section{FIBER TENACITY AND ELONGATION}

The results of analysis of fiber tenacity and elongation at break are shown in Table V. These indicate that there is no significant effect of opening roller speed on tenacity and elongation at the $99 \%$ - confidence level. We believe the reason for this is that the fibers are caught by the pins at one point only along their length, and they are not damaged throughout their whole length. If a fiber break occurs at any point, the length of the fiber shortens, but this does not inflict any significant tenacity loss on the shortened fiber.

\section{YARN PROPERTIES}

The results of the analyses of yam properties within the given opening roller speed range are shown in Table VI. The relationships between such yam properties and roller speeds for various yam types are shown in Figure 2. Since fiber feeding speeds and yam delivery speeds were kept constant for all the yams produced, we saw no significant change in the yam count (Figure 2a).

Figures $2 \mathrm{~b}$ and $\mathrm{c}$ show that the higher the speed of the opening roller, the lower the yam tenacity and elongation at break for all given materials. We saw earlier (Table V) that there was not any significant effect of opening roller speed on fiber tenacity and elongation at break. Therefore, the decrease of these two yarn properties at high opening roller speeds can be attributed to two factors. First, since fiber breakage increases with increasing opening roller speed, the effective fiber length decreases, causing weaker yams to be produced. Second, we showed in our earlier study [14] that as the speed of the 
opening roller increases, fiber straightness and degree of alignment along the yarn deteriorate, again producing weaker yarns.

TABLE V. Values of fiber tenacity and elongation.

\begin{tabular}{lcc}
\hline Fiber sample & Tenacity, g/rex & Elongation, \% \\
\hline C & 22.4 & 5.3 \\
C4 & 23.3 & 5.6 \\
C5 & 24.4 & 5.6 \\
C6 & 26.6 & 5.6 \\
C7 & 26.6 & 5.5 \\
C8 & 23.1 & 5.3 \\
C9 & 23.9 & 5.3 \\
P & 52.6 & 30.2 \\
P6 & 52.0 & 29.6 \\
P7 & 52.0 & 28.8 \\
P8 & 52.0 & 30.1 \\
P9 & 50.6 & 27.7 \\
V & 22.3 & 26.1 \\
V4 & 20.0 & 22.9 \\
V5 & 22.3 & 26.5 \\
V6 & 20.8 & 23.8 \\
V7 & 20.0 & 22.3 \\
V8 & 20.0 & 22.9 \\
V9 & 20.0 & 22.8 \\
A & 22.9 & 23.4 \\
A5 & 22.9 & 25.5 \\
A6 & 22.9 & 25.1 \\
A7 & 22.1 & 24.8 \\
A8 & 22.1 & 24.9 \\
A9 & 22.1 & 24.1 \\
\hline
\end{tabular}

TABLE VI. Results of the analysis of the yam characteristics.

\begin{tabular}{|c|c|c|c|c|c|c|c|c|c|c|c|c|c|c|c|}
\hline \multirow{3}{*}{$\begin{array}{c}\text { Yarn } \\
\text { samples }\end{array}$} & \multirow{2}{*}{\multicolumn{2}{|c|}{$\begin{array}{c}\text { Yarn count, } \\
\text { tex }\end{array}$}} & \multirow{2}{*}{\multicolumn{2}{|c|}{$\begin{array}{l}\text { Tenacity, } \\
\text { cN/tex }\end{array}$}} & \multirow{2}{*}{\multicolumn{2}{|c|}{$\begin{array}{c}\text { Elongation, } \\
\%\end{array}$}} & \multirow{2}{*}{\multicolumn{2}{|c|}{ Twist, $\mathrm{T} / \mathrm{m}$}} & \multicolumn{2}{|c|}{ Irregularity } & \multirow{3}{*}{$\begin{array}{l}\text { Thin } \\
\text { places/ } \\
\text { km }\end{array}$} & \multirow{3}{*}{$\begin{array}{l}\text { Thick } \\
\text { places/ } \\
\text { lmm }\end{array}$} & \multirow{3}{*}{$\begin{array}{c}\text { Neps/ } \\
\mathrm{km} \\
(+280 \%)\end{array}$} & \multirow{2}{*}{\multicolumn{2}{|c|}{ Hairiness }} \\
\hline & & & & & & & & & Im & $c V_{m}$ & & & & & \\
\hline & $\bar{x}$ & $\% \mathrm{CV}$ & $\overline{\mathrm{x}}$ & $\% \mathrm{CV}$ & $\bar{x}$ & $\% \mathrm{CV}$ & $\overline{\mathrm{x}}$ & $\% \mathrm{CV}$ & q & $\%$ & & & & H & Sh \\
\hline $\mathrm{Cl} 4$ & 29.9 & 1.8 & 11.7 & 6.4 & 6.5 & 4.5 & 891 & 2.6 & 11.45 & 13.06 & 28 & 22 & 8 & 6.23 & 1.67 \\
\hline $\mathrm{C} 15$ & 29.7 & 1.2 & 11.0 & 6.0 & 6.8 & 4.7 & 915 & 2.4 & 10.16 & 12.74 & 3 & 8 & 0 & 6.58 & 1.49 \\
\hline $\mathrm{Cl} 6$ & 30.0 & 1.0 & 10.0 & 7.0 & 6.5 & 6.4 & 925 & 2.0 & 9.58 & 11.82 & 5 & 0 & 0 & 6.12 & 1.43 \\
\hline $\mathrm{Cl} 7$ & 29.7 & 1.3 & 9.9 & 7.9 & 6.2 & 6.8 & 941 & 2.0 & 9.37 & 11.77 & 5 & 0 & 0 & 6.00 & 1.37 \\
\hline $\mathrm{C} 18$ & 29.8 & 0.9 & 8.9 & 6.9 & 5.8 & 5.5 & 938 & 2.2 & 9.51 & 11.96 & 5 & 0 & 0 & 6.06 & 1.36 \\
\hline $\mathrm{Cl} 9$ & 30.4 & 0.5 & 9.1 & 5.4 & 5.9 & 5.1 & 950 & 2.3 & 9.64 & 12.12 & 0 & 0 & 0 & 6.13 & 1.36 \\
\hline P16 & 30.9 & 1.5 & 14.9 & 13.0 & 9.6 & 5.5 & 725 & 3.0 & 10.42 & 13.05 & 10 & 8 & 0 & 7.47 & 1.64 \\
\hline $\mathrm{P} 17$ & 30.6 & 0.7 & 12.3 & 15.0 & 8.7 & 4.8 & 729 & 3.1 & 10.02 & 12.58 & 8 & 3 & 0 & 7.37 & 1.71 \\
\hline P18 & 30.9 & 0.8 & 8.2 & 10.5 & 7.1 & 7.0 & 719 & 2.8 & 10.79 & 13.62 & 10 & 30 & 3 & 7.45 & 1.77 \\
\hline P19 & 29.8 & 0.7 & 8.5 & 10.6 & 7.8 & 9.1 & 777 & 3.5 & 11.91 & 15.03 & 55 & 38 & 20 & 7.37 & 1.74 \\
\hline V14 & 28.6 & 0.7 & 11.9 & 7.8 & 10.4 & 8.0 & 762 & 2.2 & 12.31 & 15.82 & 60 & 198 & 25 & 5.94 & 1.28 \\
\hline V15 & 29.3 & 1.0 & 10.2 & 8.5 & $\cdot 10.3$ & 7.6 & 776 & 3.7 & 12.80 & 17.29 & 73 & 383 & 165 & 6.31 & 1.42 \\
\hline V16 & 29.1 & 1.0 & 11.7 & 6.7 & 11.1 & 4.8 & 763 & 2.2 & 8.75 & 10.98 & 0 & 0 & 0 & 6.36 & 1.35 \\
\hline V17 & 29.7 & 0.8 & 10.5 & 7.1 & 10.0 & 6.8 & 757 & 2.6 & 9.50 & 11.86 & 0 & 0 & 0 & 6.70 & 1.44 \\
\hline V18 & 29.6 & 1.0 & 8.8 & 8.2 & 9.5 & 7.0 & 776 & 2.1 & 9.36 & 11.76 & 0 & 3 & 0 & 6.98 & 1.50 \\
\hline V19 & 29.4 & 1.0 & 8.6 & 9.0 & 9.4 & 8.8 & 778 & 2.1 & 11.09 & 13.75 & 0 & 3 & 0 & 7.27 & 1.51 \\
\hline A16 & 29.6 & 1.7 & 12.5 & 9.2 & 20.8 & 12.6 & 595 & 2.4 & 11.01 & 13.86 & 18 & 30 & 3 & 9.19 & 1.95 \\
\hline A17 & 30.5 & 0.8 & 12.2 & 7.0 & 20.8 & 6.3 & 601 & 2.6 & 9.42 & 11.81 & 3 & 0 & 0 & 10.06 & 2.05 \\
\hline A18 & 29.9 & 3.7 & 11.9 & 4.8 & 9.7 & 6.5 & 574 & 2.9 & 9.42 & 11.81 & 0 & 3 & 0 & 10.35 & 2.13 \\
\hline $\mathrm{A} 19$ & 30.4 & 0.8 & 9.7 & 9.8 & 15.1 & 10.0 & 640 & 4.4 & 10.11 & 12.73 & 10 & 3 & 0 & 9.91 & 2.10 \\
\hline
\end{tabular}


The correlation coefficients between fiber breakage and yam tenacity are $-0.920,-0.866,-0.835$ and 0.981 for cotton, polyester, viscose, and acrylic, respectively. These correlation coefficients show significant trends indicating the relationship between yarn tenacity and fiber breakage that occurs during the opening process. The ranges of opening roller speeds in which the most significant yarn tenacity decreases occurred were between 7000 and $8000 \mathrm{rpm}$ for cotton and viscose, 6000 and $8000 \mathrm{rpm}$ for polyester, and 8000 and 9000 rpm for acrylic.

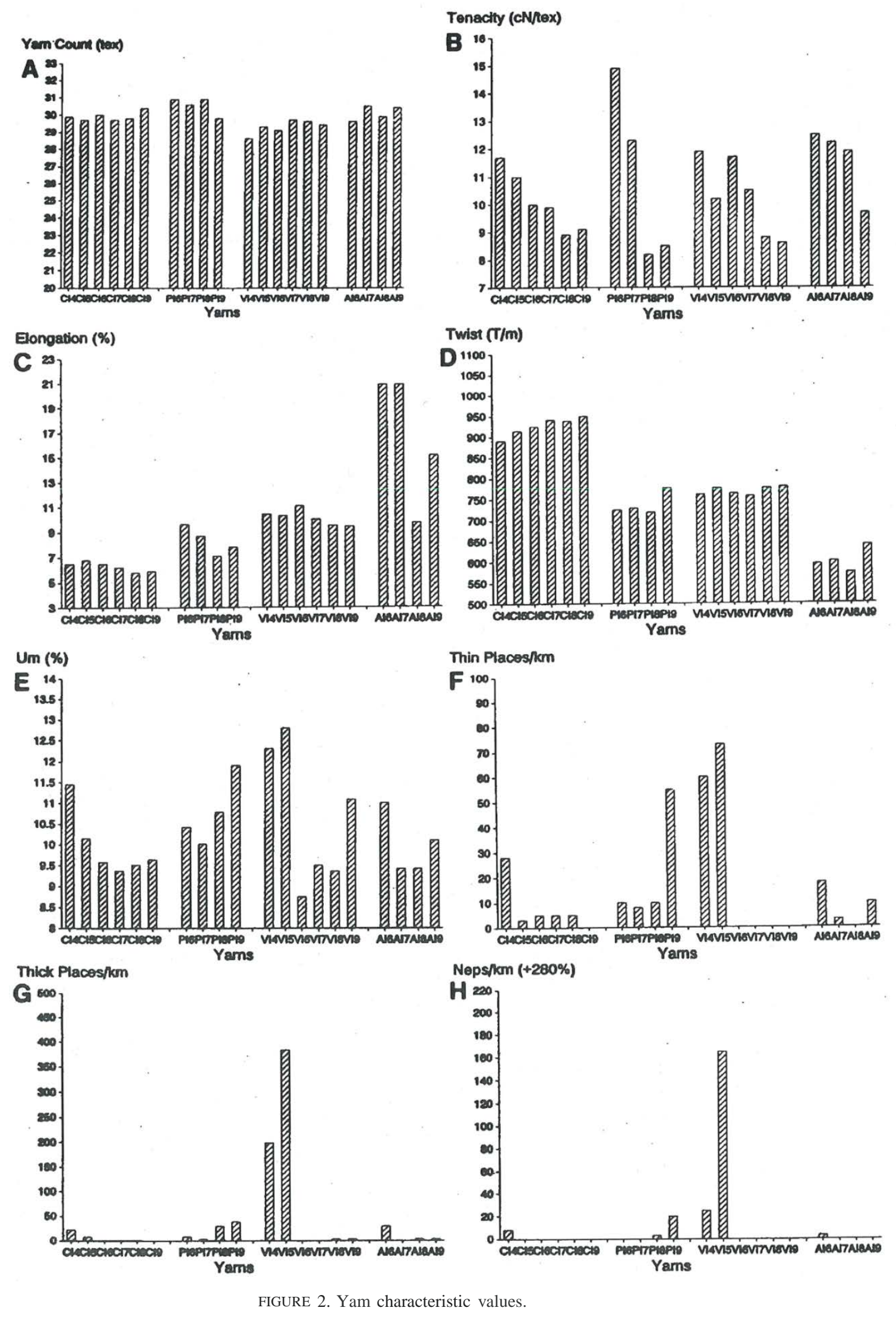


The correlation coefficients between opening roller speed and twist (calculated from the data presented in Table VI) are $0.949,0.707,0.438$, and 0.506 for cotton, polyester, viscose, and acrylic fibers, respectively. These values show that there is only a small degree of association between these two factors. The slightly increased twist number for the high opening roller speeds can be attributed to the high degree of fiber separation at high speeds ( Figure 2d).

Figures 2e-h show the measured values of yarn irregularities, such as Um (\%), thin places/ km (-50\%), thick places/ km (+50\%), and neps/ km (+280\%) for the given yarns. The effect of opening roller speed on these yarn irregularities varies from one material to another. The high yam irregularities at low and high speeds can be attributed to a low degree of opening at low speeds and high fiber breakage and low fiber alignment at high speeds.

\section{Conclusions}

The opening roller in an open-end spinning system causes fiber damage of varying degrees, differing from one material to another. As the speed of the opening roller increases, fiber breakage becomes higher.

The choice of the opening roller speed can therefore significantly affect the resulting yam properties. There is much deterioration in the yam when it is processed at high opening roller speeds. This deterioration is mainly detected in yarn tenacity, elongation, evenness, and imperfections due to high fiber breakage and low fiber straightness, which we found in previous work at high speeds (Ulku et al. [14]). Therefore, we can conclude that both fiber breakage and fiber straightness play a significant role in determining yarn properties. Extensive deterioration in yarn evenness and imperfections occurs at low opening roller speeds due to the low degree of fiber opening in the opening stage (Ulku et al. [14]). Since responses to changes in opening roller speeds are so different from one material to another, we cannot recommend a definite optimum speed range.

\section{ACKNOWLEDGMENTS}

We would like to thank Platt Saco Lowell (UK) Ltd. for their support in undertaking this work, particularly for producing the yarns used for testing. We are also grateful to Loughborough University of Technology for making its facilities available for this re- search. Special thanks are due to Bozkun Mensucat. A.S., Mensucat Santral, A.S., Sagem, and Sonmez Pamuklu Sanayi, A.S. for the assistance received in the fiber and yarn tests. Ulku also would like to acknowledge Uludag University for the financial support she received.

\section{Literature Cited}

1. Abadear, E. F., The Effect of Opening Roller Speed on the Properties of Open-End Spun Yams, Masters thesis, UMIST, Dept. of Textiles, 1976.

2. Bownass, R., Recent Researches in Woolcombing, J. Textile Ins1. SI, 1035-1047 (1960).

3. Chattopadhyay, R. and Sinha, T. K., Length Distribution Pattern of Broken Parts of Cotton Fibre Generated during Fibre Separation in Rotor Spinning. Ind. J. Textile Res. 13 (9), 143-145 (1988).

4. Dyson, E., A Study of Open-End Spinning by Circumferential Assembly with Especial Reference to the Spinning of Modified Rayon, Part I: Fibre Presentation, J. Textile Inst. 6S, 588-594 (1974).

5. Dyson, E. and Happey, F., An Experimental Study of Woolcombing, J. Textile Inst. SI, 1016-1029 (1960).

6. Machinery News Digest, Opening Fibres in OE Spinning-A Comparison of Czech and French Approaches. Textile Month (6), 90 (1979).

7. Mansour, S. A. and El Messiry, M. A., Change in Fibre Length Properties During Processing on 0. E. Spinning Machine, Invest. Inform. Textil Tensioactivos 29, (1/2), 37-51 (1986).

8. Ozipek, B., Effects of Fiber Properties of Acrylics on Rotor Spinning, Textile Res. J. S6 (6), 35-4-363 (1986).

9. Salhotra, K. R., and Chattopadhyay. R., Incidence and Mechanism of Fiber Breakage in Rotor Spinning. Textile Res. J. 52(5), 317-320 (1982). 
10. Malhotra, K. R. and Chattopadhyay, R., Loss in Fiber Tenacity During Separation in Rotor Spinning. Textile Res. J. 54(3), 194-197 (1984).

11. Salhotra, K. R., Kambo, N. S., and Chattopadhyay, R., A Probability Model for Estimating Fiber Breakage in Rotor Spinning, Textile Res. J. S3( 7 ), 435-438 ( 1983).

12. Sikder, M. D. Abdus Satter, PSL Master Spinner: 1bc Effect of Machine Parameters on Yam Properties, Master's thesis, UMIST, Dept. of Textiles, 1989.

13. Simpson, J. and Murray, M. F., Effects of Combing. Roll Wire Design and Rotor Speed on Open End Spinning and Cotton Yam Properties, Textile Res. J. 49(9), 505-512 (1979).

14. Ulku, S., Acar, M., King. T. G. and Ozipek. B., Fiber Alignment and Straightening in Opening for Open-End Spinning, Textile Res. J. 63(6), 309-312 (1993). 